\title{
Advancing Quality Health Care through Continuing American Board of Medical Specialties Board Certification
}

\author{
Lois Margaret Nora, MD, JD
}

Quality is a core value of the medical profession. Board certification, morbidity and mortality conferences, and participation in hospital quality committees are just a few of the many ways in which the medical profession has evidenced its commitment to quality throughout the decades. Despite this fundamental commitment to quality, the health professions and health care industry have been slower to embrace quality science and continuous quality improvement (QI) practices than were manufacturing and engineering. Resistance to implementing formalized QI systems often was justified by financial concerns and the belief that health care is fundamentally different from those sectors that more readily embraced QI principles.

At this point, however, the value of adopting and implementing quality science in health care has become clear. For financially challenged hospitals, cost reduction is a factor. ${ }^{1,2}$ For patients and health care providers, as highlighted in the Institute of Medicine's Crossing the Quality Chasm, ${ }^{3}$ the health care environment involves substantial dangers that are better addressed by systems improvement than by individual blame. For policymakers, national health care expenditures remain unsustainable and pose a danger to our nation's economic stability. The field of QI offers solutions, and organizations that adopt QI strategies have demonstrated improved patient outcomes, cost reductions, and higher employee satisfaction. ${ }^{1,2,4,5}$ Over time,

From the American Board of Medical Specialties, Chicago, IL. Funding: none.

Conflict of interest: The author is from the American Board of Medical Specialties.

Corresponding author: Lois M. Nora, MD, JD, American Board of Medical Specialities, 222 N. LaSalle St., Suite 150, Chicago, IL 60601-1117 (E-mail: lmnora@ABMS.org).

\section{See Related Article on Page 626.}

champions of quality science in health care, such as the Institute for Health Care Improvement, have emerged and gained new adherents by highlighting best practices and offering educational resources. ${ }^{6}$

The evolving understanding of quality can be seen in the history of the American Board of Medical Specialties (ABMS) board certification movement. The first ABMS member board, the American Board of Ophthalmology, was founded in 1916 to improve the safety and quality of eye care provided to patients through the elevation of educational standards and a voluntary examination process. ${ }^{7}$ Beginning with the American Board of Family Medicine (ABFM), which since its founding has offered only periodic, timelimited board certification, all the ABMS member boards eventually transitioned from "lifetime" to time-limited board certification. In 2000, all 24 ABMS member boards adopted a 4-part framework of career-long professional learning and assessment (Maintenance of Certification [MOC]), which links ongoing learning and assessment activities to continuing certification.

Quality science is incorporated into the MOC program in several ways. The 4-part framework of MOC incorporates (1) licensure and professional standing; (2) lifelong learning and self-assessment; (3) cognitive expertise; and (4) practice performance assessment. ${ }^{8}$ Physicians who are unfamiliar with the principles of QI and patient safety can earn Part II MOC credit by completing approved coursework in these topics. ABMS member boards may incorporate questions about QI and patient safety into their Part III MOC examinations. In fulfillment of Part IV of MOC, many physicians engage in Plan-Do-Study-Act cycles or other QI methods of improving patient care, either in their individual practices or in the health systems in which their patients receive care.

The findings by Peterson et al, ${ }^{9}$ reported in this issue of the Fournal of the American Board of Family 
Medicine, contribute to our understanding of the incorporation of quality science and QI activities into the practice of medicine. Of a convenience sample of family physicians who accessed their online ABFM physician portfolios and completed a survey during a 2 -week period in $2011,38 \%$ reported that they had participated in a QI activity in the past year. The responding physicians were younger, probably because of the mode of sampling and the possibility that the Plan-Do-Study-Act acronym is more familiar to younger physicians. Given the incorporation of QI activities into the ABFM's MOC program, it is not surprising, as the authors note, that those physicians who reported personal QI activity were more likely to have completed a Part IV MOC activity. The finding that there was no difference between rural and urban physicians in QI participation suggests that physicians are incorporating these activities across diverse practice types and locations. It would be interesting to know the characteristics of the QI activities undertaken by these respondents. For example, are QI activities eligible for MOC Part IV more frequent among certain groups of physicians? Are certain physicians more likely to participate in institutional QI activities rather than those focused on individual practice? Answers to these questions can be helpful in developing MOC activities to meet physicians' specific practice needs.

Continuing certification through a program for MOC is still a young concept and one that is being debated in the profession. Peterson and colleagues ${ }^{9}$ remind us of key reasons for continuing certification and processes for MOC. Quality science, patient safety, and systems intervention to improve patient care were largely nonexistent areas of study when many currently practicing physicians were in medical school and residency. MOC has been an important method of introducing these new concepts and skills into the physician community. Furthermore, MOC requirements have increased the availability of learning resources for practicing physicians as provided by specialty societies, the ABMS member boards, and other education providers. It is fair to conclude that MOC has contributed to the diffusion of QI knowledge and practices across the entire profession. QI is only one of many innovations that regularly occur as medical science and clinical practice continually evolve. Programs for MOC are in and of themselves important QI processes designed for continuous improvement of physicians and for public assurance that the physician is engaged in ongoing learning and assessment.

A review of the current ABMS standards for MOC has been under way for the past 18 months. Three QI-related themes have emerged in this discussion. First, there is strong consensus that meaningful QI activities undertaken as part of MOC can contribute to better patient outcomes, improved stewardship of resources, and greater patient and physician satisfaction. Second, there is broad interest in encouraging physician engagement in QI projects that cross traditional disciplinary boundaries and engage the entire health care team. Third, there is an expectation that each ABMS member board will participate in its own QI activities designed to increase the relevance, ease of use, meaningfulness, and impact of its MOC program. The proposed standards for the ABMS 2015 Program for MOC will be available for public comment in fall 2013 on the AMBS website (www.abms.org) and considered for approval in January 2014.

The past decade has seen dramatic advances in the formal incorporation of QI across the continuum of medical education and into health care delivery environments. However, there is more to be done. First, QI information has been widely introduced into required medical school coursework, and during the past 5 years nearly 17,000 health professions students and residents have earned the Basic Certificate from the Institute for Health Care Improvement Open School. ${ }^{10,11}$ Successful QI training programs have been developed in residencies, and the Accreditation Council on Graduate Medical Education's Clinical Learning Environment Review Program fosters and studies the inclusion of postgraduate trainees into institutional QI activities. ${ }^{12,13}$ The Association of American Medical College's Aligning Forces for Quality Program assists academic health centers' efforts to align medical education and staff development with QI efforts and patient safety goals. ${ }^{14}$ In the next phase of educational development, we should identify ways to leverage successful initiatives and better integrate QI into interprofessional health care education.

Second, the proposed 2015 MOC standards will continue to encourage physicians to focus MOC Part IV QI activities on issues important to their individual practices, and the standards also will facilitate physicians' involvement in cross-disciplinary, team-based, and organization-wide QI activities. Going forward, is it possible to engage with 
communities, identify health issues important to those communities, and then target QI initiatives that are eligible for Part IV MOC toward those issues? The Oregon START (Screening Tools and Referral Training) Program has demonstrated the power of MOC-approved QI activities to increase the developmental screening of children, increase the identification and referral of children for services, and improve the appropriateness of referrals. ${ }^{15}$ The American College of Physicians is sponsoring an MOC-eligible QI activity designed to increase adult immunization rates, and Illinois internists plan to take this initiative statewide. ${ }^{16,17}$ Imagine the possibilities if groups of physicians deliberately use MOC Part IV QI initiatives to improve the health of communities.

Finally, MOC QI activities should align with other physician-adopted initiatives that foster evidence-based decision making and effective stewardship of resources. For example, the Choosing Wisely campaign, initiated by the ABIM Foundation and currently engaging more than 50 specialty societies, has generated lists of diagnostic and therapeutic interventions that patients and physicians should question based on the evidence-based indications in a particular case. ${ }^{18}$ Should the development of new MOC Part IV QI activities be influenced by the Choosing Wisely campaign? If so, how?

The ABFM and many other ABMS member boards require MOC Part IV activities on a 3-year cycle. The goal toward which we should all strive is the continuous and enthusiastic engagement of physicians in MOC activities, including QI activities, because they find these activities meaningful and user friendly and because they are confident that these activities make a positive difference in the lives of patients, the health of communities, and their own enjoyment of practice.

\section{References}

1. Sollecito WA, Johnson JK. McLaughlin and Kaluzny's continuous quality improvement in health care. 4th ed. Burlington, MA: Jones and Bartlett Learning; 2013.

2. Going lean in health care. IHI Innovation Series white paper. Cambridge, MA: Institute for Healthcare Improvement; 2005. Available from: http://www.ihi.org/ knowledge/Pages/IHIWhitePapers/GoingLeaninHealth Care.aspx. Accessed August 14, 2013.

3. Institute of Medicine. Crossing the quality chasm: a new health system for the 21 st century. Washington, DC: National Academics Press; 2003.
4. Sherbourne CD, Edelen MO, Zhou A, Bird C, Duan $\mathrm{N}$, Wells KB. How a therapy-based quality improvement intervention for depression affected life events and psychological well-being over time: a 9-year longitudinal analysis. Med Care 2008;46:78-84.

5. Miller MR, Girswold M, Harris JM, et al. Decreasing PICU catheter-associated bloodstream infections: NACHRI's quality transformation efforts. Pediatrics 2010;125:206-13.

6. Institute for Healthcare Improvement. History. Available from: http://www.ihi.org/about/Pages/History. aspx. Accessed August 14, 2013.

7. Cordes FC, Rucker CW. History of the American Board of Ophthalmology. Am J Ophthalmol 1962; 53:243-64.

8. American Board of Medical Specialties. ABMS Maintenance of Certification. Available from: http:// www.abms.org/Maintenance_of_Certification/ABMS_ MOC.aspx. Accessed August 20, 2013.

9. Peterson LE, Jaen CR, Phillips RL. Family physician participation in quality improvement. J Am Board Fam Med 2013;26:626-7.

10. Institute for Healthcare Improvement. Open school. Overview. Available from: http://www.ihi.org/ offerings/IHIOpenSchool/overview/Pages/default. aspx. Accessed August 19, 2013.

11. Liaison Committee on Medical Education. LCME Annual Medical School Questionnaire - Part II (2012-2013), accessed from the records of the American Medical Association, August 16, 2013.

12. Tudiver F, Click IA, Ward P, Basden JA. Evaluation of a quality improvement curriculum for family medicine residents. Fam Med 2013;45:19-25.

13. Accreditation Council for Graduate Medical Education. Clinical Learning Environment Review (CLER) program. Overview. Available from: http://www.acgmenas.org/cler.html. Accessed August 10, 2013.

14. Association of American Medical Colleges. Aligning and Educating for Quality. Available from: http:// www.aamc.org/initiatives/cei/ae4q/181950/more about_ae4q.html. Accessed August 10, 2013.

15. Henderson M. Maintenance of certification: ABCD III state efforts to capitalize on an incentive for quality improvement. Portland, ME: National Academy for State Health Policy; 2012.

16. Hall LL, Beru AY, Karp S. Primary Care Network Use of Cloud-based Technology for Education and QI: ACPMedconcert Pilots. Presented at Alliance for Continuing Education of Health Professions, January, 2013.

17. American College of Physicians, Illinois Chapter. Immunization week in the Downstate Dialogue. Available from: http://www.acponline.org/about_acp/chapters/ il/dd_sept2013.pdf. Accessed September 27, 2013.

18. Choosing wisely [homepage]. Philadelphia: ABIM Foundation. Available from: http://www.choosingwisely. org. Accessed August 20, 2013. 